\title{
The use of haemopoietic growth factors in blood disorders
}

\author{
Ian M Hann
}

Over the last nine years we have witnessed an explosion in knowledge about haemopoietic growth factors. Those that are available or will be shortly are listed in the table, along with the shorthand term for the agent, the chromosome containing the gene for this product, and the cell or cells that are its target.

Decisions about the use of these growth factors are often dictated by what doctors believe is a cost-benefit analysis. The argument is that we cannot really afford to use such expensive new drugs and so we seek to produce some sort of financial equation into which we clearly can enter cost, but there is no easy mechanism to assess benefit. However, now that we are in possession of the results of a number of trials, we do know that there has been in general no reduction in mortality for patients treated with growth factors, but there have been benefits, in more rapid recovery of the blood counts. In some of the trials this has been translated into reduction in the use of antibiotics and length of hospital stay. To limit length of stay has recently become a benefit within the British health care system, where treating more patients brings in more money from purchasers than having single patients in hospital for a long time.

There is a need to state all of this because at this moment in time we are still awaiting completion of some of the crucial randomised trials of efficacy and toxicity of growth factors. At the same time, benefit is often clinically apparent and withholding possibly effective treatment in potentially life threatening situations is clearly a difficult decision.

This type of problem was epitomised in a recent American review of the subject when, after the Food and Drug Administration approved uses of haemopoietic factors had been clearly defined, the following statement

Haemopoietic growth factors

\begin{tabular}{|c|c|c|c|}
\hline Growth factors & Abbreviation & $\begin{array}{l}\text { Chromosome } \\
\text { site for gene }\end{array}$ & Target cell(s) \\
\hline \multirow{5}{*}{$\begin{array}{l}\text { (A) Lineage restricted } \\
\text { Granulocyte colony } \\
\text { stimulating factor } \\
\text { Erythropoietin } \\
\text { (B) Lineage non-restricted } \\
\text { Granulocyte macrophage } \\
\text { stimulating factor } \\
\text { Interleukin 3 } \\
\text { c-Kit ligand (or) } \\
\text { Stem cell factor }\end{array}$} & G-CSF & 17 & Granulocytes \\
\hline & Epo & 7 & Red cells \\
\hline & GM-CSF & 5 & Granulocytes + macrophages \\
\hline & $\begin{array}{l}\text { IL-3 } \\
\text { cKl (or) }\end{array}$ & 5 & \multirow[t]{2}{*}{ Early haemopoietic progenitors } \\
\hline & SCF & 12 & \\
\hline
\end{tabular}

was made: 'Yet the use of these growth factors, as outlined above, is much more widespread. There are many medical as well as economic issues that remain to be addressed before such widespread use is justified. Even within the limited framework in which their use has been studied, questions remain.' Within the limitations dictated by these factors and the ever changing nature of the subject, I will attempt to describe my current reading of the situation. I will not address specifically the area of anaemia secondary to renal dysfunction or prematurity because this would be better dealt with by specialists elsewhere. Erythropoietin will be dealt with separately as apart from these situations its use is experimental. Thereafter it appeared more suitable to deal with specific diseases one by one.

\section{Erythropoietin}

Recombinant human erythropoietin has been available for nine years ${ }^{1}$ and we have the additional advantage of a readily available radioimmunoassay. ${ }^{2}$ It has an established role in the treatment of anaemia of chronic renal insufficiency that has been recently reviewed ${ }^{3}$ and will not be further discussed. Its use in other situations where it may be of value, for example anaemia in HIV infected patients, anaemia of chronic inflammatory disorders, myelodysplastic syndromes, and anaemia of prematurity are still under investigation. ${ }^{3}$ Studies in aplastic anaemia, ${ }^{4}$ Fanconi's anaemia, ${ }^{5}$ and sickle cell anaemia ${ }^{6}$ would not encourage me to recommend their use at the present time.

Rare cases of childhood myelodysplasia present with transfusion dependent refractory anaemia and in this circumstance, a trial of erythropoietin treatment (50-150 units/kg intravenously or subcutaneously three times a week) is justified. Ultimately these patients may develop leucopenia or thrombocytopenia or an excess of leukaemic blasts, when alternative treatment such as bone marrow transplantation would have to be considered. ${ }^{7}$ Treatment can to some extent be guided by the erythropoietin blood concentrations, a response in several separate situations being more likely if the concentration is less than $500 \mathrm{U} / 1$ as in some studies ${ }^{8}$ or less than $200 \mathrm{U} / 1$ as in others. ${ }^{9}$ As with other growth factors, however, one cannot entirely rely upon these 
measurements because the primary defect is not understood and could also involve growth factor receptors and abnormal postreceptor intracellular signalling. ${ }^{10}$

The use of erythropoietin in order to prevent or reduce the need for blood transfusion is a difficult issue with reference to children. Whenever a child from a Jehovah's Witness family presents with acute leukaemia or a solid tumour that requires intensive treatment, the use of alternative measures is always raised. There is no evidence yet that the use of cytokines such as interleukins IL-3, IL-6, IL-11, or thrombopoietin will reduce the need for platelet transfusions, and there are theoretical risks that these substances may stimulate the leukaemia. Recent trials have also shown that IL-3 may be poorly tolerated and more work needs to be done before widespread use would be justified. ${ }^{11} 12$ However, there is a possibility that erythropoietin treatment may be of value especially in children with acute lymphoblastic leukaemia, wherein an early remission can be achieved. It is certainly unlikely to be of any value, for example in acute myeloid leukaemia where the re-emergence of functional erythroid progenitors after treatment is usually long delayed.

Autologous blood transfusion has become less of an issue with the re-establishment of public confidence in donating to the blood transfusion service, whereas barely a week went by in the mid-1980s without strident demands for directed donor or autologous blood supplies; this is very rarely requested now. Clearly in any case there was very little work on this subject in the paediatric field. There is no doubt that severe logistic difficulties lie in the way and there is a very real risk of doing more harm than good. Having said all of that, if appropriate resources were to be made available, I believe that the time is right for feasibility studies in older children with approximately predictable needs. Studies in this area will require careful assessment of the fitness of the patient for the procedure. It must also be understood that the optimal dose, route, and interval of erythropoietin use with or without autologous blood harvesting, have yet to be answered. In adults, however, it has been shown to reduce the need for allogeneic blood in several trials, ${ }^{13} 14$ and this will need to be weighed against the large cost and theoretical toxicity such as thromboembolic events. ${ }^{15}$

Severe congenital neutropenia (Kostmann's syndrome), cyclical neutropenia, and neutropenia with glycogen storage disease type Ib

Management of these disorders is the big success story of growth factor treatment. Granulocyte colony stimulating factor (G-CSF) was shown early on to be more effective than granulocyte macrophage colony stimulating factor (GM-CSF) ${ }^{16}$ and is now established first line treatment. ${ }^{17}$ In the past Kostmann's syndrome was associated with a high mortality, severe morbidity, from recurrent infections and the only curative treatment was allogeneic bone marrow transplantation, with all its attendant problems. ${ }^{18}$ Not only is G-CSF well tolerated, but formal studies have shown improvement in energy, social integration, functional ability, satisfaction with life, school attendance, and reduced hospital admissions. ${ }^{19}$ Similar good results have been achieved with cyclical neutropenia ${ }^{18}$ and neutropenia associated with glycogen storage disease type $\mathrm{Ib} .^{20}$

The dose of G-CSF required to maintain neutrophils above $1.0 \times 10^{9} / 1$ varies from patient to patient. The usual approach is to give a starting dose of $6 \mu \mathrm{g} / \mathrm{kg}$ subcutaneously twice a day (once a day in cyclical neutropenia). Stepwise increments of dosage are then given over a period of a month until the neutrophils reach $1.5 \times 10^{9} / 1$. Downward adjustments are made if the neutrophils reach $10 \times 10^{9} /$. It must be remembered that patients with cyclical neutropenia continue to 'cycle' but at a higher level consistent with a good clinical response. In general, responses are apparent within a few days of starting treatment and $80 \%$ of patients do respond with a mean G-CSF dose of $11.5 \mu \mathrm{g} / \mathrm{kg} /$ day in Kostmann's syndrome and $5.75 \mu \mathrm{g} / \mathrm{kg} /$ day in cyclical neutropenia. ${ }^{17}$ Even those who do not respond optimally often have a useful clinical response.

This group of patients is very important because they have been followed for up to five years of treatment in almost all cases; the responses have been maintained and antibodies to treatment have not developed. ${ }^{17}$ Also, some patients can be maintained on as low a dose as $1 \mu \mathrm{g} / \mathrm{kg} /$ day which would be of greater cost-benefit if the manufacturers reduced the actual dose in each vial. Another important fact is that the neutrophils produced in response to G-CSF appear to function well. ${ }^{21}$ Assessment of side effects after prolonged treatment is crucial and will provide general lessons for chronic usage. The acute toxicity is mild and usually transient and consists usually of mild bone pains. ${ }^{17}$ Other side effects such as skin rashes, arthralgias, low platelet counts, and splenomegaly (presumably due to extramedullary haemopoiesis) are infrequent and rarely significant. More worrying is the occurrence of leukaemia and myelodysplasis often with a monosomy 7 in at least four children. ${ }^{17}$ Kostmann's syndrome is known to be associated with an increased frequency of leukaemia. ${ }^{22}$ Theoretically, myeloid growth factors could influence these changes or make the underlying abnormality more easily detected. I believe that this should emphasise very strongly to all of us the need for careful continuous assessment of these agents in the same way as for other new drugs. There has been a tendency to imagine that they are free of side effects and that randomised trials of efficacy are not necessary. I hope that it is clear that such feelings are unjustified.

It needs to be said at this point that, save for the superiority of G-CSF over GM-CSF in the management of severe congenital neutropenia, there is insufficient evidence available to allow a choice between these drugs in other situa- 
tions. Unfortunately, it would also appear that there is little enthusiasm for comparative studies, which means that we will have to make judgments based on comparisons of toxicity and efficacy acquired from non-randomised trials. The strong impression, and that is all it can be unless trials of G-CSF versus GM-CSF are carried out, is that G-CSF is better tolerated and associated with less in the way of myalgia, fluid retention, rashes, and fever. ${ }^{23}$ Generally efficacy appears equivalent but in certain situations, especially where one is looking for synergy with other growth factors (for example IL-3 plus GM-CSF or G-CSF in amegakaryocytic thrombocytopenia), and especially for effects on platelets, as in severe aplastic anaemia, then this may not be true.

\section{Severe aplastic anaemia}

Preliminary studies show that G-CSF or GM-CSF may have activity in patients with severe aplastic anaemia, although this response may be transient and most helpful in the least severely affected patients. ${ }^{2324}$ At the present time there is at least one randomised multicentre trial that is investigating the role of 'standard' (antilymphocyte globulin and cyclosporin and corticosteroid) treatment with and without the addition of G-CSF. Until we know the outcome of that study, growth factors do not have an established role in the management of severe aplastic anaemia.

\section{Fanconi's anaemia and other constitutional aplastic anaemias}

Patients with Fanconi's anaemia have DNA repair and somatic defects. ${ }^{25}$ There is a constitutional aplastic anaemia that, like that occurring in Shwachman-Diamond syndrome and dyskeratosis congenita, often progresses to severe pancytopenia. ${ }^{26}$ In all of these disorders G-CSF or GM-CSF has proved to be of some value in alleviating neutropenia and reducing the risk of infection. ${ }^{26-28}$ It is possible that selected cases may benefit from this treatment, although the thrombocytopenia and bleeding problems negate most of its worth. Also, Shwachman-Diamond syndrome and Fanconi's anaemia are disorders with a strong propensity to leukaemic 'transformation' and thus the risks of treatment largely outweigh the advantages. IL-3 has been used in Fanconi's anaemia and dyskeratosis congenita without any benefit on the platelet count. ${ }^{26}$ Thus, the mainstay of current treatment will be some form of bone marrow transplantation when pancytopenia or leukaemic change requires this approach.

\section{Amegakaryocytic thrombocytopenia}

There has been one study of the use of IL-3 with or without GM-CSF treatment in the management of this very rare severe congenital thrombocytopenia with absent progenitor cells. ${ }^{29}$ At the present time transfusions, supportive care, and possibly bone marrow transplantation are the only options and most patients die of bleeding or the complications of subsequent pancytopenia. ${ }^{30} \mathrm{~A}$ response to IL-3 occurred in all patients, although only two of the six patients became transfusion independent. Three other patients initially required no platelet treatment, but this was not sustained. Thus, when a donor is not available, a trial of treatment would be worthwhile and further studies of the use of thrombopoietic factors (for example IL-6, IL-11, and thrombopoietin) are warranted. This study also demonstrates features that have sometimes been shown in other trials of prolonged cytokine treatment, that is loss of continued response and late responses. Thus, this makes the point that such trials require long treatment periods and careful follow up.

\section{Blackfan-Diamond anaemia}

Most patients with this rare form of pure red cell aplasia present in early infancy and respond to steroid treatment and can often be maintained fit and well on a very small dose. About one third of patients either have no response or relapse on steroids and become refractory even to increased doses of prednisolone. The only alternative is the institution of a blood transfusion programme with subcutaneous desferrioxamine iron chelation, or bone marrow transplantation. ${ }^{31}$

Three series of transfusion dependent patients have been treated with IL- 3 at daily subcutaneous doses of $0.5-10 \mu \mathrm{g} / \mathrm{kg}$. Thirty patients in total were treated and six experienced significant responses, with marked reduction or discontinuation in transfusion requirement. ${ }^{26}$ It was possible to obtain a sustained improvement for one to two years in two patients after a six week course. Two patients required maintenance treatment for more than a year. Two patients, however, discontinued treatment after development of deep venous thrombi. Thus, this treatment can be considered where transfusion programmes are poorly tolerated or compliance with iron chelation is not obtained. Meanwhile, further studies of the use of c-kit ligand (stem cell factor, steel factor, mast cell growth factor) ${ }^{32}$ and other cytokine treatments are required.

\section{Myelodysplastic syndromes ${ }^{7}$}

Children with these disorders have a relatively poor prognosis, related to leukaemic transformation or infection and bleeding related to cytopenias. A number of small studies of the use of GM-CSF${ }^{33}$ and G-CSF ${ }^{34}$ in adults have shown elevations in neutrophils in some patients, with consequent reduction in infectious episodes. Some patients also had rises in platelet count with GM-CSF that reduced the need for transfusions. Similar results have been achieved with IL- $3^{34}$ and the dose used $\left(250-500 \mu \mathrm{g} / \mathrm{m}^{2}\right.$ subcutaneously daily for 15 days) was associated with mild side effects consisting of fever, backache, local erythema, and bone pain. To date there have been no studies in children.

The only curative treatment for myelo- 
dysplasia at present is bone marrow transplantation ${ }^{7}$ and there are well documented cases wherein the malignant clone has been stimulated by the use of growth factors, even though the opposite can sometimes occur. ${ }^{34}$ Thus, in patients who do not have a donor the use of GM-CSF or IL-3 may tide the patients over episodes of bleeding and infection, but otherwise, their use is currently limited to prospective trials. ${ }^{35}$

\section{Bone marrow graft failure}

G-CSF and GM-CSF are being used more and more often in patients who fail to engraft or lose a graft after bone marrow transplantation. ${ }^{36}$ More than a hundred adults have been treated in this way and the survival rates have doubled, compared with patients who were treated previously with various immunomodulatory methods or regrafting. The effect on long term marrow recovery remains undefined. Whether the addition of growth factors such as IL-3, IL-6, IL-11, and thrombopoietin will improve matters further by prompting platelet recovery, remains to be seen.

\section{Neutropenia follow chemoradiotherapy}

A recent randomised placebo controlled study has studied the use of G-CSF in patients with non-myeloid malignancy. ${ }^{37}$ This was a large group of patients undergoing allogeneic bone marrow transplantation or high dose chemoradiotherapy with autologous marrow rescue, mainly for acute lymphoblastic leukaemia and solid tumours.

A significant reduction in use of antibiotics, total parenteral nutrition, and days in hospital was demonstrated. All of the patients became profoundly neutropenic at about a week after transplant and thus the incidence of infection was not altered, but the duration was. This was due to a more rapid neutrophil count recovery. Not surprisingly, there was no effect on the platelet count. Most of the previous smaller non-randomised studies have also pointed in the same direction and it would seem to me that this is a cost effective approach. There is evidence that one can start later in the course of the transplant (for example at eight days after marrow infusion and using $5 \mu \mathrm{g} / \mathrm{kg} /$ day of G-CSF in this study) there will be a cost saving. ${ }^{38}$ Theoretically this could be even further enhanced by the use of stem cells harvested from peripheral blood by the use of cell separators. The donation can be improved by carrying out the harvest after chemotherapy and/or stimulation with G-CSF or GM-CSF ${ }^{39}$ or combinations of growth factors in vitro or ex vivo. This may negate the need for bone marrow harvesting and avoid general anaesthesia. There are major technical problems, however, with the collection of stem cells in young children. Randomised studies of the use of this approach have at last started up and will address the problems of harvesting young donors and potentially stimulating significant numbers of circulating malignant cells. At present the approach is experimental and it must not be assumed by anyone that it is as yet of proved value.

Outside of the bone marrow transplant field, growth factors (mainly G-CSF and GM-CSF) are already being widely used despite the fact that there are very few randomised studies and even fewer in children. With regard to myeloid leukaemia, there is a real risk of accelerating the disease as some leukaemia cells express the myeloid growth factor receptors. This may possibly be turned to advantage by using the growth factors to recruit leukaemic cells into cycle before cytotoxic chemotherapy, ${ }^{39}$ although this approach is only at a very early stage of development. There is also preliminary evidence that G-CSF may be safe to use in the stimulation of neutrophil recovery after marrow transplantation for acute myeloid leukaemia (AML). ${ }^{40}$ At the present moment use of G-CSF and GM-CSF is often used in extremis in children with AML where previously granulocyte transfusions would have been used, for example in a profoundly neutropenic febrile patient not responding to at least six days of broad spectrum antibiotic and amphotericin B. This decision is taken as a potentially life saving measure in the knowledge that disease free survival may be compromised. Several randomised trials of growth factor use are under way in AML and should clarify the situation.

In a similar fashion to its use in AML, almost any severely neutropenic child not responding to conventional antimicrobial treatment is considered a candidate for G-CSF or GM-CSF treatment, as opposed to the previous option of granulocyte transfusions. There are precious few studies of this situation in children and those carried out in adults have usually been carried out in a preventative/prospective way and have not been randomised or associated with an analysis of morbidity or cost. In general if G-CSF or GM-CSF are given with myelosuppressive chemotherapy, there has been a reduction in the period of neutropenia and sometimes fewer days on antibiotics. ${ }^{41-43}$ However, I do not believe that this should be adopted in any similar situation in children at the present time until proper large randomised studies have been completed. As with AML, if full conventional antimicrobial treatment is clearly failing then I would give G-CSF $5 \mu \mathrm{g} / \mathrm{kg} /$ day because it is very well tolerated and may potentially be life saving.

\section{Conclusion}

I hope that I have made it clear that haemopoietic growth factors are new and deserve to be tested out in the same way as other drugs. There are a few established indications but we are now basically in an exciting era that must not be marred by a temptation to bypass the need for randomised trials in order to establish their proper role.

\footnotetext{
1 Lin FK, Suggs $\mathrm{S}$, Lin $\mathrm{CH}$, et al. Cloning and expression of the human erythropoietin gene. Proc Natl Acad Sci USA the human erythro

2 Sherwood JB, Goldwasser E. A radio-immunoassay for erythropoietin. Blood 1979; 54: 885-93.
} 
3 Goodnough LT, Anderson KC, Kurtz S, et al. Indications and guidelines for the use of hematopoietic growth factors. Transfusion 1993; 33: 944-59.

4 Hirashima $\mathrm{K}$, Bessho $\mathrm{M}$, Jimmai I. Improvement in anaemia by recombinant human erythropoietin in patients with myelodysplastic syndrome and aplastic anemia. Contrib Nephrol 1991; 88: 254-65.

5 Das RE, Milne A, Rowley M, Smith EC, Cotes PM. Serum immunoreactive erythropoietin in patients with idiopathic aplastic and Fanconi's anaemia. Br $\mathcal{F}$ Haematol 1992; 82: aplastic ar.7.

6 Rodgers GP, Dover GJ, Uyesaka N, Noguchi CT, Schechter AN, Nienhuis AW. Augmentation by erythropoietin of the fetal hemoglobin response to hydroxyurea in sickle cell disease. $N$ Engl F Med 1993; 328: 73-80.

7 Passmore SJ, Hann IM, Stiller CA. Pediatric myelodysplasia: a study of 69 children and a new prognostic scoring system. Blood 1994 (in press).

8 Fischl M, Galpin JE, Levine JD, et al. Recombinant human erythropoietin for patients with AIDS treated with zidovudine. N Engl $f$ Med 1990; 322: 1488-93.

9 Bowen DJ, Culligan D, Jacobs A. The treatment of anaemia in the myelodysplastic syndromes with rh-epo. $\mathrm{Br} f$ Haematol 1991; 77: 419-23.

10 Rauprich P, Kyas U, Pietsch T, Steffens U, Weltke K. Normal G-CSF receptor expression and altered intracellular protein phosphorylation in neutrophils from patients with severe congenital neutropenia. Blood 1991; 78 (abstract suppl 1): 105a.

11 Nemunaitis J, Applebaum FR, Singer JW, et al. Phase I trial with recombinant human IL-3 in patients with lymphoma undergoing autologous bone marrow transplantation. Blood 1993; 82: 3273-8.

12 Nand S, Sosman J, Godwin JE, Fisher RI. A phase I/II study of sequential IL-3 and GM-CSF in myelodysplastic syndromes. Blood 1994; 83: 357-60.

13 Goodnough LT, Rudrick S, Price TH, et al. Increased pre-operative collection of autologous blood with th-erythropoietin therapy. $N$ Engl $f$ Med 1989; 321: 1163-8.

14 Mercuriali F, Zanella A, Barosi G, et al. Use of erythropoietin to increase the volume of autologous blood donated by orthopaedic patients. Transfusion 1993; 33: 55-60.

15 Goodnough LT, Price TH, the EPO Study Group. A phase III trial of rh-erythropoietin therapy in non-anemic orthopaedic patients subjected to aggressive autologous blood phlebotomy: dose, response, toxicity and efficacy. Transfusion 1994 (in press).

16 Welte K, Zeidler C, Reiter A, et al. Differential effects of G-CSF and GM-CSF in children with severe congenital neutropenia. Blood 1990; 75: 1056-63.

17 Dale DC, Bonilla MA, Davis MW, et al. A randomized controlled phase III trial of rhG-CSF for the treatment of severe chronic neutropenia. Blood 1993; 81: of severe

18 Rappoport JM, Parkman R, Newburger P, Camitta $M$, Chusid M. Correction of infantile agranulocytosis by allogeneic bone marrow transplantation. Am F Med 1980; 68: 605-9.

19 Jones EA, Boylard AA, Dale DC. Quality of life of patients with severe neutropenia receiving long-term treatment with G-CSF. FAMA 1993; 270: 1131-3.

20 Wang WC, Crist WM, Ihle JN, Arnold BA, Keating JP. G-CSF corrects the neutropenia associated with glycogen storage disease type Ib. Leukaemia 1991; 5: 347-9.

21 Rösler J, Emmerdörffer A, Elsner J, et al. In vitro functions of neutrophils induced by treatment with rh-GCSF in severe congenital neutropenia. Eur f Haematol 1991; 46: 112-8.

22 Rosen RB, Kang S. Congenital agranulocytosis terminating in acute myelomonocytic leukemia. 7 Pediatr 1979; 94: 406-8.

23 Guinan EC, Sieff CA, Oette DH, Nathan DG. A phase I/II trial of rGM-CSF for children with aplastic anaemia. Blood 1990; 76: 1077-82.

24 Kojima S, Fukuda M, Miyajima Y, Matsuyama T, Horibe $\mathrm{K}$. Treatment of aplastic anaemia in children with rhG-CSF. Blood 1991; 77: 937-41.

25 Nilsson LR. Chronic pancytopenia with multiple congenital abnormalities (Fanconi's anaemia). Acta Paediatrica 1960; 49: 519-29.

26 Gillio AP, Gabrilove IL. Cytokine treatment of inherited bone marrow failure syndromes. Blood 1993; 81: $1669-74$

27 Paley C, Murphy S, Karayalcin G, et al. Treatment of neutropenia with rhG-CSF. Blood 1991; 78 (abstract suppl 1): $3 \mathrm{a}$.

28 Guinan E, Nathan D, Huhn R, Lopez K, Oldham F. Phase I/II trial of rhGM-CSF in patients with Fanconi's anaemia. Blood 1991; 78 (abstract suppl 1): 97a.

29 Guinan EC, Lee YS, Lopez KD, et al. Effects of IL-3 and GM-CSF on thrombopoiesis in congenital amegakaryocytic thrombucytopenia. Blood 1993; 81: 1691-98.

30 Alter BP, Young NS. The bone marrow failure syndromes. In: Nathan DG, Oski FA, eds. The hematology of infancy and childhood. Philadelphia: WB Saunders, 1992: 216

31 Lenarsky C, Weinberg K, Guinan E, et al. Bone marrow transplantation for constitutional pure red cell aplasia. Blood 1988; 71: 226-9.

32 Sieff $C$, Guinan E. In vitro enhancement of erythropoiesis by Steel factor in Diamond-Blackfan anaemia and treatment of other congenital cytopenias with IL-3/GM-CSF. Stem Cells 1993; 11 (suppl 2): 113-22.

33 Vadhan-Raj S, Keating M, Le Maistre A, et al. Effects of rhGM-CSF in patients with myelodysplastic syndromes. $N$ Engl f Med 1987; 317: 1545-52.

34 Kobayashi Y, Oyabe T, Ozawa K, et al. Treatment of myelodysplastic syndromes with recombinant rhG-CSF; a preliminary report. Am $\mathcal{F}$ Med 1989; 86: 178-82.

35 Ganser A, Seipelt G, Lindemann A, et al. Effects of rhIL-3 in patients with myelodysplastic syndromes. Blood 1990; 76: 455-62.

36 Nemunaitis J, Singer JW, Buckner CD, et al. Use of rhGMCSF in graft failure after bone marrow transplantation. Blood 1990; 76: 245-53.

37 Gisselbrecht C, Prentice HG, Bacigalupo A, et al. Placebocontrolled phase III trial of lenogastrum in bone marrow transplantation. Lancet 1994; 343: 696-700.

38 Khawja A, Mills W, Leveridge $\mathrm{K}$, Goldstone AH, Linch DC. Efficacy of delayed G-CSF after autologous BMT. Bone Marrow Transplant 1993; 11: 479-82.

39 Giralt S, Escudier S, Kantariian IT, et al. Preliminary results of treatment with filgastrim for relapse of leukemia and myelodysplasia after allogeneic bone marrow transplantamyelodysplasia after allogeneic bone mart

40 Takahashi S, Okamoto S-I, Shirafuji N, et al. RhG-CSFcombined regimen for allogeneic transplantation in refractory acute myeloid leukaemia. Bone Marrow Transplant 1994; 13: 239-45.

41 Santana VW, Bowman LC, Furman WL, et al. Trial of chemotherapy plus rhG-CSF in children with advanced neuroblastoma. Med Pediatr Oncol 1990; 18: 395A.

42 Furman WL, Fairclough DL, Huhn RD, et al. Therapeutic effects and pharmacokinetics of rhGM-CSF in childhood cancer patients receiving myelosuppressive chemotherapy. $\mathcal{F}$ Clin Oncol 1991; 9: 1022-8.

43 Furman WL, Fairclough DL, Cain AM, et al. The use of GM-CSF in children after high dose chemotherapy. Med Pediatr Oncol 1992; suppl 2: 26-30. 